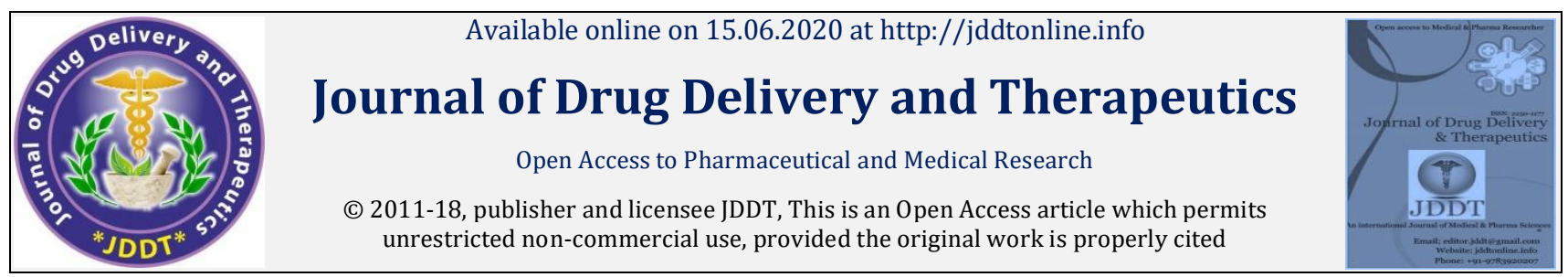

Open $\odot$ Access

Research Article

\title{
Sexual Violence and its Associated Factors among Female High School Students in Southern Ethiopia: A Cross-Sectional Study
}

\author{
${ }^{1 *}$ Koyra Hailu, ${ }^{2}$ Argo Mekuanint, ${ }^{3}$ Kara Niguse, ${ }^{3}$ Tufa Efrata \\ ${ }^{1}$ School of Pharmacy, College of Health Sciences and Medicine, Wolaita Soddo University, P.O.Box 138, Soddo, Ethiopia \\ 2 Program Officer at JSI, Hawassa, Ethiopia \\ ${ }^{3}$ School of Public Health, College of Health Sciences and Medicine, Wolaita Soddo University, P.0.Box 138, Soddo, Ethiopia
}

\begin{abstract}
Background: Sexual violence is a major concern of society as physical and mental harm endured by women is extremely destructive. However, little is known about sexual violence within the study area. Therefore, current study aimed to assess the prevalence and associated factors of sexual violence among female high school students in Soddo town, Southern Ethiopia.
\end{abstract}

Methodology: A cross sectional study was conducted using pretested, structured self-administered questionnaire. Data analysis was done using SPSS and the presence of association was assessed using bivariate test. Multivariable logistic regression was used to control confounding effects and the strength of association was estimated in odds ratio with $95 \%$ confidence interval.

Results: The prevalence of life time rape among female students was found to be $25.8 \%$. The odds of experiencing life time rape was higher among students who had more than one sexual partner (AOR=9.11; 5.52,15.04). Substance abuse is significantly associated with life time rape that the chance of experiencing rape among students who were chewing chat was higher $(\mathrm{AOR}=6.09 ; 1.57,23.69)$ than their counterparts.

Conclusion: High level of rape among female high school students was found in Sodo town. Chewing chat and having more than one sexual partner had statistically significant association with life time rape.

Keywords: Sexual violence, Wolaita, Ethiopia, Soddo

Article Info: Received 12 March 2020; Review Completed 22 May 2020; Accepted 06 June 2020; Available online 15 June 2020

Cite this article as:

Hailu K, Mekuanint A, Niguse K, Efrata T, Sexual Violence and its Associated Factors among Female High School Students in Southern Ethiopia: A Cross-Sectional Study, Journal of Drug Delivery and Therapeutics. 2020; 10(3-s):150-158 http://dx.doi.org/10.22270/jddt.v10i3-s.4121

*Address for Correspondence:

Koyra Hailu, School of Pharmacy, College of Health Sciences and Medicine, Wolaita Soddo University, P.0.Box 138, Soddo, Ethiopia

\section{INTRODUCTION}

The World Health Organization (WHO) defines sexual violence as: 'Any sexual act, attempt to obtain a sexual act, unwanted sexual comments or advances, or acts to traffic or otherwise directed against a person's sexuality using coercion, by any person regardless of their relationship to the victim, in any setting, including but not limited to home and work ${ }^{1}$.

Violence against women is the world's most prevalent, pervasive, and systemic problem. It is a problem without borders, a universal scourge on women and their families that knows no geographical boundaries, culture or wealth. Data from country and local studies indicate that, in some parts of the world at least one woman in every five has suffered an attempted or completed rape ${ }^{2}$.
Sexual violence, including sexual harassment, frequently occurs in institutions assumed to be 'safe', such as schools, where perpetrators include peers and teachers. In studies from around the world, including Africa, south Asia, and Latin America, studies have documented that substantial proportions of girls report experiencing sexual harassment and abuse on the way to and from school, as well as on school and university premises, including classrooms lavatories and dormitories, by peers and by teachers 3 .

In Ethiopia different studies indicated that women and school adolescents are highly perpetrated. Studies indicated that significant proportions of secondary school female adolescents in Ethiopia have been sexually abused. For instance a study conducted in Debrebirhan high school students indicated that the life time prevalence of completed rape among the study subjects was $13.2 \%$. A number of factors that make individuals vulnerable to sexual 
Violence have been identified; female sex history of past abuse; poverty; war/armed conflict; psychological or cognitive vulnerability; single parent homes; social isolation (e.g., lacking an emotional support network); parents with mental illness, or alcohol or drug dependence 4,5 .

Several consequences of sexual Violence of girls and boys including physical, psychological and social problem, and the consequence can be immediate as constraining their educational performance, risk to Human Immune Deficiency Virus (HIV), Sexually Transmitted Infections (STI) and the late consequence could be social isolation, fear, phobia and hopelessness ${ }^{6}$.

In the context of Ethiopian situation since there are no enough studies on prevalence and consequences of sexual Violence against female adolescents in general and in Wolaita Sodo in particular, this study was aimed to assess the prevalence of sexual violence and associated factors among female adolescent high school students in Wolaita Sodo town. It is relevant to look into the problem so as to have more information which will help for policy makers and organizations working with adolescents to design intervention measures.

\section{MATERIALS AND METHODS}

\section{Study setting and period}

Soddo town is one of the towns that are found in Wolaita zone and it is the main site of zonal administrative offices. Wolaita Soddo is located $380 \mathrm{kms}$ to the south of Addis Ababa and $155 \mathrm{Kms}$ from Hawassa which is the capital city of SNNPR. There are 105, 591 people living in Sodo town. The educational institutions found in the town are seven high schools out of which three governmental and four private that consists a total of 3074 female students that are taken as target population for the study and one preparatory school, one TVET college and other primary and secondary level schools and one University with in the town. The study was conducted from

\section{December 2014 to February 2015.}

Study design; school based cross-sectional study design was employed.

Study population; all randomly selected female high school students in Wolaita town, registered for the fiscal year 2014/15

Inclusion criteria; regular grade nine and ten female students were included in the study.

Exclusion criteria; students who were not willing to consent during questionnaire administration and disabled were excluded.

Sample size determination: the sample size was determined by using standard single population proportion formula.

$$
\mathrm{n}=(\mathrm{Z} \alpha / 2)^{2} \mathrm{p}(1-\mathrm{p}) / \mathrm{d}^{2}
$$

In this study $0.37 \%$ prevalence, with $95 \%$ confidence interval and marginal error $0.04 \%$, additionally $10 \%$ was added to compensate for non-response and non-complete questions. Where $\mathrm{n}$, refers to sample size, $\mathrm{P}$, represents prevalence of sexual violence. D represents margin of error, $\mathrm{Z} \alpha / 2$ represents critical value at $95 \%$ confidence level of certainty (1.96). Initially calculated sample size is 480 and final sample size with $10 \%$ none response, $\mathbf{5 2 8}$.

Sampling procedure: a simple random sampling technique was employed to select grade nine and ten female students from each high school of Sodo town. There are seven high schools in Sodo town. The school consists of grades 9 and 10 and there are sections in each grade labeled as A, B, C, D, etc.... The total sample size was allocated by probability proportional to size (PPS) to the seven schools in the town. PPS was used again to allocate the calculated sample size to grade nine and ten students. Then the rosters of the students were used as sampling frame. Finally, from both grade levels female students were selected by simple random sampling technique.

\section{Study Variables}

\section{Dependent variable: Sexual Violence}

Independent variables: Socio-demographic characteristics, age, ethnicity, religion, marital status, age at first sex, number of sexual partner substance use such as drinking alcohol, chewing chat, smoking, residence, family income, living arrangement of the students, parents' educational status, parental living arrangement.

\section{Data collection method and procedure}

A pre-tested, structured, anonymous self-administered questionnaire was used adopted from ${ }^{2,7}$. The questionnaire is first prepared in English and then translated back to Amharic language for simplicity and translated back to English for checking consistency by two different individuals who speak both English and Amharic fluently. Data collection was facilitated by two BSc Nurses from December to February 2015. The data collectors were clearly briefed about the purpose of the research and importance of strictly getting only the sampled subjects. Training on the data collection methods was given. In order to maintain confidentiality, separate rooms for students were arranged ahead within each selected school. The sitting arrangement of the participants also considered: All the selected girls were called and made to sit in prior arranged rooms within their own school compound. To make the data collection procedure easy for the investigator and supervisor the data collection was conducted one school at a time and proceed to the other step by step. Each student took a single seat with sparse arrangement of chairs and desks. No names or identifier was included on the questionnaire.

Data quality management: The principal investigator and supervisors were made a close supervision on the data collection process. To check the accuracy and validity of the questionnaire, pre-test was done on 26 high school female students prior to the actual data collection period in Bodity high school, which is outside and adjacent woreda to Soddo town. The result of pretest was discussed and relevant change and correction were made on the questionnaires.

Data analysis procedures: The data were coded, entered and cleaned using Epi-Info version 3.5.1 and analysis was done using SPSS for Windows version 16.0. For assessing the strength of the associations and their statistical significance, Odds Ratio (OR) and 95\% CI was calculated for each independent variable against the dependent variables by using binary logistic regression. To control for potential confounders and to observe the independent effect of explanatory variables on the dependent variables multivariate analysis was employed using logistic regression models. All variables having significant association in the crude odds ratio considered as important factors were used in multivariate analysis. The result was presented by using absolute numbers, frequencies, odds ratio and confidence interval. 


\section{Operational definitions}

Sexual violence: it is to commit sex using force when somebody doesn't want to. It includes completed rape and sexual harassment.

Rape: any penetrative form of sexual act in terms of vaginal intercourse without the consent of the respondent.

Sexual harassment: refers to intended or on purpose strong verbal expression and threat against female students, when somebody [perpetrator] failed his plan to gratify one's sexual interest which is unwelcome by the recipient.

Attempted rape: the attempt to have non-consensual sexual intercourse with a female student whereby she was having a chance of escaping the attempt.

Ethical consideration: Ethical clearance was obtained from Wolaita Sodo University ethical review committee. A formal letter was also submitted to Sodo town educational office and to each high school of Sodo town where the study takes place. Oral and written permissions from the schools and the respective study subjects were taken. The main objectives of the study were explained and their consent to participate in the study was assured before completing the questionnaire.

\section{RESULTS}

\section{Socio-Demographic Characteristics of Study Subjects}

From a total of 528 study participants required for the study, 515 female students were involved, yielding $97.5 \%$ of response rate. Thirteen respondents were excluded due to grossly incomplete and inconsistent responses. From the total students, $303(58.8 \%), 212(41.2 \%)$ were grade nine and ten respectively. Four hundred forty nine $(87.2 \%)$ of the students were in the age range of 15 and 19 with the mean age of $15.8 \pm 1.4$ SD years.

Majority 321 (62.3\%), of respondents were Protestants, $463(89.9 \%)$ were Wolaita and $50(9.7 \%)$ of them were married. About $313(62.3 \%)$ grew in urban areas. With regard to the living arrangement, $374(72.6 \%)$ of the respondents were living with parents, 29 (5.5\%) were living with their husband, 20 (3.9\%) of students were living alone (Table 1).

\section{Family history}

Majority, $106(20.6 \%)$ of the student's fathers were attained grade $9-12$, similarly $109(21.2 \%)$ of the student's mothers also attained grade $9-12$. About $354(68.7 \%)$ of the students' parents were living together, $257(50 \%)$ of the student's family earns monthly income of more than 1000 ETB about $211(41 \%)$ of the students lived in Soddo town for nine years and above (Table 2).

Table1: Socio-demographic characteristic of female students in Wolaita Sodo town, Feb 2015. (n=515)

\begin{tabular}{|c|c|c|}
\hline Variable & Number & percent \\
\hline \multicolumn{3}{|l|}{ Age of the respondent } \\
\hline $10-14$ & 60 & 11.7 \\
\hline $15-19$ & 449 & 87.2 \\
\hline$>=20$ & 6 & 1.2 \\
\hline \multicolumn{3}{|c|}{ Religion of the respondent } \\
\hline Orthodox & 161 & 31.3 \\
\hline Protestant & 321 & 62.3 \\
\hline Catholic & 10 & 1.9 \\
\hline Muslim & 12 & 2.3 \\
\hline Others & 11 & 2.1 \\
\hline \multicolumn{3}{|c|}{ Grade level of the respondent } \\
\hline grade nine & 303 & 58.8 \\
\hline grade ten & 212 & 41.2 \\
\hline \multicolumn{3}{|c|}{ Place of growth of the respondents } \\
\hline urban & 313 & 60.8 \\
\hline rural & 202 & 39.2 \\
\hline \multicolumn{3}{|c|}{ Marital status of the respondents } \\
\hline single & 445 & 86.4 \\
\hline married & 50 & 9.7 \\
\hline divorced & 16 & 3.1 \\
\hline widowed & 4 & 0.8 \\
\hline \multicolumn{3}{|c|}{ Living arrangement of the respondent } \\
\hline with husband & 29 & 5.6 \\
\hline with father and mother & 374 & 72.6 \\
\hline with relatives & 70 & 13.6 \\
\hline alone & 20 & 3.9 \\
\hline with friends & 22 & 4.3 \\
\hline
\end{tabular}

\section{Substance Use}

From the total respondents of habit of substance use, chewing chat was practiced by $31(6.0 \%)$ of the respondents and from which $13(41.9 \%)$ were chewing chat every day. Fifteen $(2.9 \%)$ smoke cigarette and $20(3.9 \%)$ drink alcohol (Table 3). 
Table2: Family history of female students in Wolaita Sodo town, Feb2015. (n=515)

\begin{tabular}{|c|c|c|}
\hline Variable & Number & Percent \\
\hline \multicolumn{3}{|c|}{ Current parental living status } \\
\hline living together & 354 & 68.7 \\
\hline separated & 30 & 5.8 \\
\hline divorced & 18 & 3.5 \\
\hline only mother alive & 57 & 11.1 \\
\hline only father alive & 21 & 4.1 \\
\hline both not alive & 35 & 6.8 \\
\hline \multicolumn{3}{|c|}{ Father educational status of the respondents } \\
\hline Illiterate & 59 & 11.5 \\
\hline read and write & 46 & 8.9 \\
\hline 1-4 grade & 59 & 11.5 \\
\hline $5-8$ grade & 94 & 18.3 \\
\hline $9-12$ grade & 106 & 20.6 \\
\hline certificate/diploma & 49 & 9.5 \\
\hline degree and above & 102 & 19.8 \\
\hline \multicolumn{3}{|c|}{ Mother educational status of the respondents } \\
\hline Illiterate & 90 & 17.5 \\
\hline read and write & 50 & 9.7 \\
\hline 1-4 grade & 96 & 18.6 \\
\hline 5 -8 grade & 77 & 15.0 \\
\hline $9-12$ grade & 109 & 21.2 \\
\hline certificate/diploma & 44 & 8.5 \\
\hline degree and above & 49 & 9.5 \\
\hline \multicolumn{3}{|c|}{ Monthly income of respondents' parent or relatives (in Birr) } \\
\hline $0-500$ & 127 & 24.7 \\
\hline $501-1000$ & 130 & 25.3 \\
\hline$>1000$ & 257 & 50.0 \\
\hline \multicolumn{3}{|c|}{ Number of years that the respondent lived in Soddo } \\
\hline$<=1$ year & 39 & 7.6 \\
\hline $2-4$ year & 150 & 29.1 \\
\hline 5-8 year & 115 & 22.3 \\
\hline >=9 year & 211 & 41.0 \\
\hline
\end{tabular}


Table 3: Substance use among female students in Wolaita Sodo town, Feb, 2015 (n=515)

\begin{tabular}{lll}
\hline Variables & Number & Percent \\
\hline Chewing chat & 31 & 6.0 \\
Yes & 484 & 94.0 \\
No & 13 & \\
\hline Chewing frequency & 18 & 51.9 \\
Every day & & 58.1 \\
Occasionally & 15 & \\
\hline Smoking cigarette & 500 & 2.9 \\
Yes & & 97.1 \\
No & 4 & 26.7 \\
\hline Smoking frequency & 11 & 73.3 \\
Every day & & \\
Occasionally & 20 & 3.9 \\
\hline Alcohol consumption & 495 & 96.1 \\
Yes & & \\
No & 6 & 30.0 \\
\hline Drinking frequency & 14 & 70.0 \\
Every day & & \\
Occasionally & & \\
\hline
\end{tabular}

\section{Sexual Experience}

From the total respondents $167(32.4 \%)$ reported that they had sexual experience preceding the data collection time. Majority of 104(62.3\%) were started sexual intercourse at the age of between 10-14 years. The mean age and SD for having the first sexual intercourse was found to be $14.1 \pm 1.5$ year. More than half of 128 (76.6\%) of the sexually active respondents reported that they had experienced at least one sexual partner in their life time.

From a total of 167 respondents who reported that they are sexually active, $28(16.8 \%)$ initiated sexual intercourse due to engagement in marriage, $20(12 \%)$ due to peer influence, $13(7.8 \%)$ being forced to have sex without their consent (Table 4).

Table 4: Sexual history among female students in Wolaita Sodo Town, Feb2015 (N=167)

\begin{tabular}{lll}
\hline Variables & Number & Percent \\
\hline Sexual intercourse & 167 & 32.4 \\
yes & 348 & 67.6 \\
no & & \\
& & \\
\hline Age at which sex started & 104 & 62.3 \\
$10-14$ & 63 & 37.7 \\
$15-19$ & & \\
& & \\
\hline Life time Sexual partner & 128 & 76.6 \\
one & 39 & 23.4 \\
>=two & & \\
& & \\
\hline Reasons for initiating first sexual intercourse & 28 & 16.8 \\
engagement in marriage & 88 & 52.7 \\
own willingness & 20 & 12.0 \\
peer pressure & 8 & 4.8 \\
to get money & 9 & 5.4 \\
to pass examination & 13 & 7.8 \\
forced & 1 & 0.6 \\
other & &
\end{tabular}

\section{Magnitude of sexual violence}

The lifetime prevalence of rape was $133(25.8 \%)$ and rape in the last 12 months was found to be $58(43.3 \%)$. The prevalence of unwanted sexual act (verbal jokes), unwelcome kissing and touching of genitalia/breast was 116(22.5\%), 99(19.2\%) and $61(11.8 \%)$ respectively (Fig 1). 


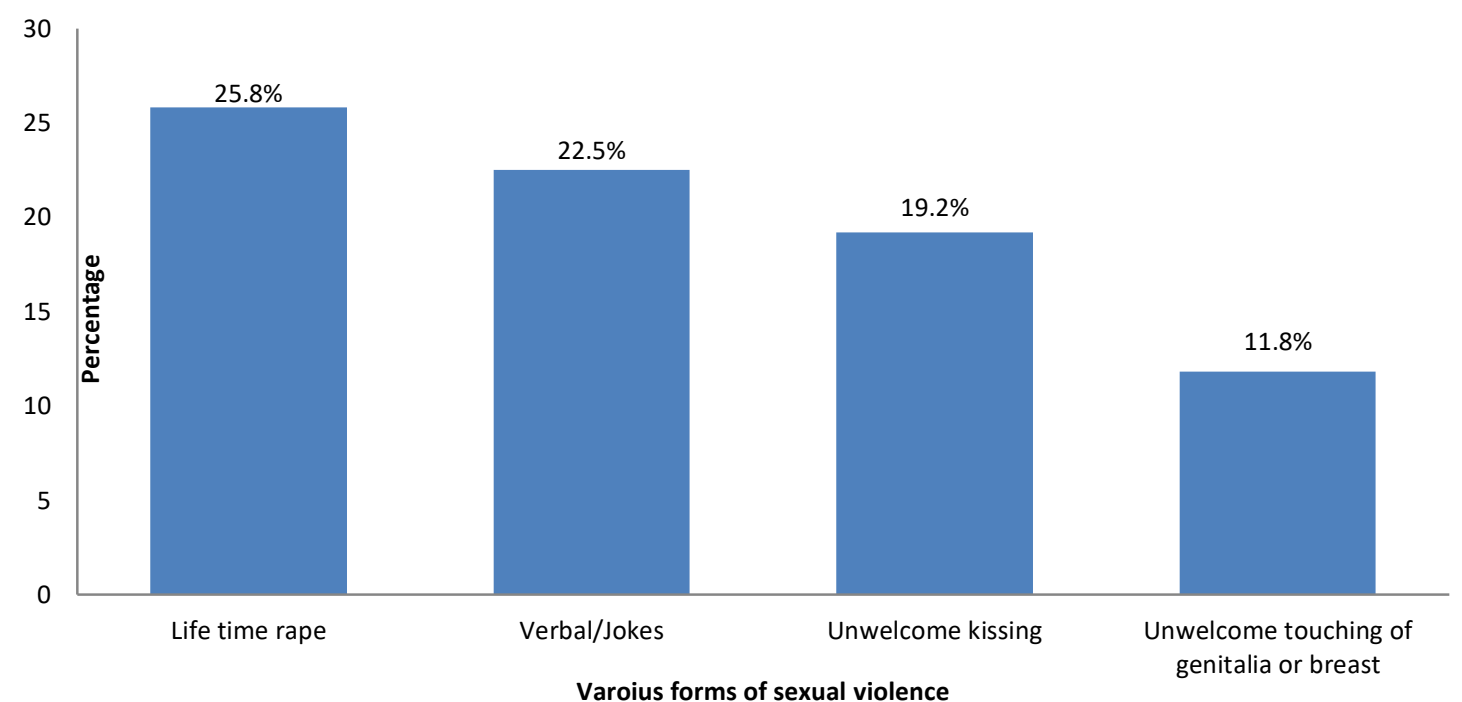

Fig 1: Magnitude of various forms of Sexual Violence among high school female students in Wolaita Sodo town, Feb 2015.

\section{Perpetrator and conditions during rape}

Regarding the perpetrators characteristics, $44(33.1 \%)$ was raped by students, followed by $23(17.3 \%)$ school teachers. However, $17(12.8 \%)$ were raped by unknown person. The mechanisms used to force the rape survivor into sex differ: $40(30.1 \%)$ reported that it was after being hit, 30(22.6\%) reported that it was after they were threatened of harm.
Among all the rape survivors, 34(25.6\%) reported that the estimated age of the perpetrator was more than 10 years as compared to their age. About $36(27.1 \%)$ reported that the perpetrators age was equal to the victim's age. With regards to the place of the act, $38(28.6 \%)$ were raped at the rapist's home, $29(21.8 \%)$ were in jungle (bush) and 16(12.0\%) were in the rapist friend's home (Table 5).

Table 5: Perpetrator characteristics and mechanism used to force among female students in Wolaita Sodo Town, Feb2015.

\begin{tabular}{|c|c|c|}
\hline Variables & Number & Percent \\
\hline \multicolumn{3}{|c|}{ Perpetuator Relationship } \\
\hline Close relative & 21 & 15.8 \\
\hline Teacher & 23 & 17.3 \\
\hline Student & 44 & 33.1 \\
\hline Friend & 22 & 16.5 \\
\hline Neighbors & 6 & 4.5 \\
\hline Others & 17 & 12.8 \\
\hline \multicolumn{3}{|c|}{ Age of the perpetuator compared to the rape survivor } \\
\hline More than 10 years & 34 & 25.6 \\
\hline $5-10$ years & 32 & 24.1 \\
\hline 1-5years & 31 & 23.3 \\
\hline Equal to my age & 36 & 27.1 \\
\hline \multicolumn{3}{|l|}{ Mechanism used } \\
\hline Hit you & 40 & 30.1 \\
\hline Pointed a knife & 23 & 17.3 \\
\hline Pointed a gun & 19 & 14.3 \\
\hline Threats of harm & 30 & 22.6 \\
\hline Made you drunk & 17 & 12.8 \\
\hline Gave you drug & 4 & 3.0 \\
\hline \multicolumn{3}{|l|}{ Place of forced sex } \\
\hline Home & 38 & 28.6 \\
\hline In school compound & 20 & 15.0 \\
\hline In the jungle & 29 & 21.8 \\
\hline Hotel & 24 & 18.0 \\
\hline Friends home & 16 & 12.0 \\
\hline Other & 6 & 4.5 \\
\hline
\end{tabular}




\section{Reporting sexual violence to the legal body}

Out of the rape survivors, 54(40.6\%) didn't share the situation to anyone and $18(13.5 \%)$ shared their situation with friends. Majority of the rape survivors, 98(73.7\%) didn't report to legal body but only 35(26.3\%) reported to police. Out of those who didn't report to the legal body, their main reasons were didn't know what to do $38(38.8 \%)$ and afraid of the parents $19(19.5 \%)$ (Fig2).

Concerning the action taken against perpetrators, up on $61(45.9 \%)$ cases no legal action was taken but up on $23(17.3 \%)$ of the perpetrator's imprisonment was taken as legal action.

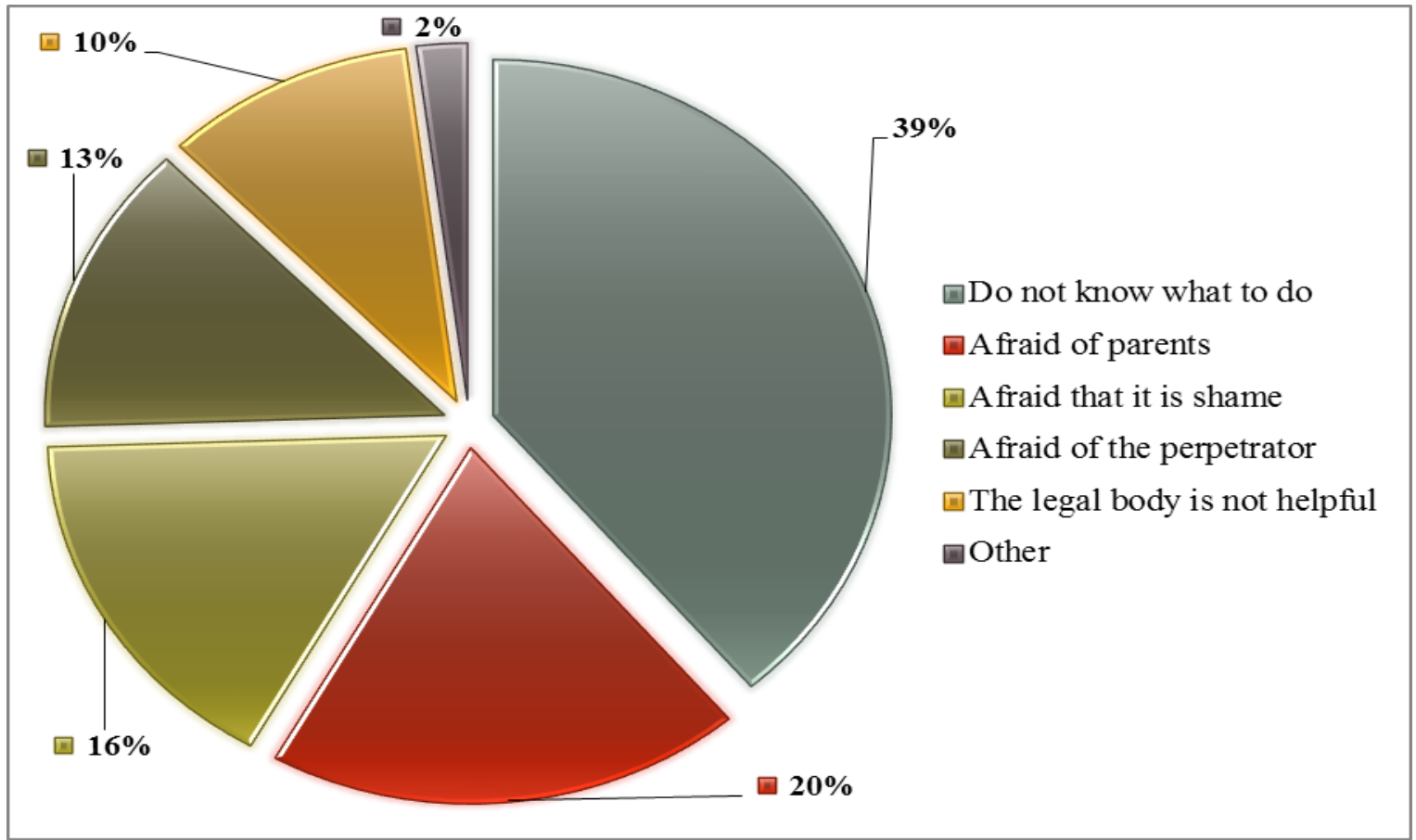

Fig.2 Reasons not to report the situation to the legal body among high school female students in Sodo town, Feb 2015

\section{Logistic regression results}

Multiple logistic regressions were done to assess factors associated with life time rape. Having more than one sexual partner and history of chat chewing had statistically significant association with rape but other variables which were significantly associated with the dependent variable in the bivariate analysis were become insignificant in the final model (Table 6).
The odds of experiencing life time rape among students who had more than one sexual partner were higher than those who had no sexual partner. (AOR= 9.11; 95\%CI: 5.52, 15.04). Students who had history of chat chewing were about six times more likely to be exposed to rape as compared to the counterparts (AOR=6.09;95\%CI:1.57,23.69). 
Table 6: logistic regression results showing the association between lifetime rape and selected variables in female students Wolaita Sodo Town, Feb 2015

\begin{tabular}{|c|c|c|c|c|}
\hline \multirow[t]{2}{*}{ Variables } & \multicolumn{2}{|c|}{ Sexual Violence } & \multicolumn{2}{|l|}{ OR(95\% CI) } \\
\hline & Yes & No & Crude OR & AOR \\
\hline \multicolumn{5}{|l|}{ Residence } \\
\hline Urban & 69 & 244 & 1.00 & 1.00 \\
\hline Rural & 64 & 138 & $1.640(1.10-2.44)$ & $1.28(0.77-2.12)$ \\
\hline \multicolumn{5}{|l|}{ Marital status } \\
\hline Married & 25 & 25 & 1.00 & 1.00 \\
\hline Single & 108 & 357 & $0.303(0.167-0.548)$ & $0.73(0.35-1.53)$ \\
\hline \multicolumn{5}{|l|}{ Grade Level } \\
\hline Grade Ten & 41 & 171 & 1.00 & 1.00 \\
\hline Grade Nine & 92 & 211 & $1.819(1.195-2.767)$ & $1.38(0.83-2.30)$ \\
\hline \multicolumn{5}{|l|}{ Chewing chat } \\
\hline No & 109 & 375 & 1.00 & 1.00 \\
\hline Yes & 24 & 7 & $11.796(4.949-28.113)$ & $6.09(1.57-23.69)$ \\
\hline \multicolumn{5}{|l|}{ Alcohol } \\
\hline No & 121 & 374 & 1.00 & 1.00 \\
\hline Yes & 12 & 8 & $4.636(1.852-11.608)$ & $0.50(0.09-2.78)$ \\
\hline \multicolumn{5}{|l|}{ Cigarette smoking } \\
\hline No & 121 & 379 & 1.00 & 1.00 \\
\hline Yes & 12 & 3 & $12.529(3.478-45.134)$ & $2.52(0.34-18.77)$ \\
\hline \multicolumn{5}{|l|}{ Father Educational Status } \\
\hline Above Secondary & 72 & 279 & 1.00 & 1.00 \\
\hline Below Secondary & 61 & 103 & $2.295(1.524-3.455)$ & $1.34(0.77-2.34)$ \\
\hline \multicolumn{5}{|l|}{ Mother Educational Status } \\
\hline Above Secondary & 55 & 224 & 1.00 & 1.00 \\
\hline Below Secondary & 78 & 158 & $2.011(1.347-3.002)$ & $1.42(0.83-2.42)$ \\
\hline \multicolumn{5}{|c|}{$\begin{array}{l}\text { Having more than one sexual } \\
\text { partner }\end{array}$} \\
\hline No & 35 & 313 & 1.00 & 1.00 \\
\hline Yes & 98 & 69 & $12.701(7.972,20.236)$ & $9.11(5.52-15.04)$ \\
\hline \multicolumn{5}{|l|}{ Living with } \\
\hline Family & 98 & 305 & 1.00 & 1.00 \\
\hline Alone & 21 & 71 & $7.348(2.760-19.565)$ & $0.96(0.50-1.84)$ \\
\hline With friends & 14 & 6 & $0.926(0.334-2.566)$ & $2.71(0.84-8.77)$ \\
\hline
\end{tabular}

\section{DISCUSSION}

In this study, the prevalence and associated factors of sexual violence was assessed among 515 female high school students. The study found out a very high prevalence of sexual violence of $79.4 \%$ which includes completed rape and sexual harassment. It is consistent with the study done in Addis Ababa, Mekele, Jimma and Hawassa with the prevalence rate ranges from $37.5-86.4 \% 2,7,8,9$.

Out of 167 sexually active participants, 13(7.8\%) started sexual activity as a result of rape but it is low when we compare this result with other studies conducted in Hawassa and Jimma Zone found that $18 \%$ and $20.4 \%$ of female students start their first sexual activity forcefully 2,8 . This indicates the severity of the problems where girls were forced into sex before they intend to do so.

The life time prevalence of rape among female high school students in Sodo town was $25.8 \%$.This finding is consistent with other studies conducted in Addis Ababa and Bahir-dar town that showed the life time prevalence of rape was found to be $21.2 \%$ and $24.3 \%$ respectively 7,10 .This finding is much lower than studies conducted in other African countries among teenagers in south west Nigeria and Urban, Zimbabwe which showed that the life time prevalence of rape was $42.1 \%$ and $33 \%$ respectively 11,12 . This discrepancy may be due to social and cultural variation between the study subjects in reporting rape. In Ethiopian context, sexual related offences particularly rape is a strong cultural norm. Moreover; the chance of engaging in marriage is considered as minimal for the female rape survivor afterwards. Therefore, they keep it secret for fear of the stigma and other negative responses from the community. From those point of views, under reporting might be there in our context.

The common perpetrators in this study were students (33.1\%) followed by school teachers $(17.3 \%)$, close friends $(16.5 \%)$ and close relatives $(15.8 \%)$.This finding is consistent with studies done in Addis Ababa, Jimma, and Tanzania among school students, that showed greater number of female respondents were perpetrated by someone they closely know and the most common perpetrators were found to be, teachers, peers, friends and close relatives 13,14 . 
From substances, chewing chat was significantly associated with lifetime rape. This finding is consistent with a study conducted in Hawassa high school students which indicated that the odds of experiencing lifetime rape was higher among chat chewers as compared to the counterparts ${ }^{2}$. This finding is also comparable with a study conducted among high school students in Eastern Harar that substance use was highly associated with lifetime rape that students who were using substances were more likely exposed to rape as compared to the nonusers 15 . This could be attributed to different reasons: substance use may influence the young women to unrealistically appraise the situation and also impair their verbal as well as physical resistance of the unwanted sexual moves of men. Substance use also exposes victims to partners who also consume substances. Similarly, men who are using substance themselves may also have impaired judgement when interacting with the young women. Therefore, young women are vulnerable to male victimizing behaviours.

\section{CONCLUSION AND RECOMMENDATION}

This study revealed high level of sexual violence among high school students in Sodo town. Substance abuse particularly, chat chewing and more than one sexual partner show statistically significant association with life time rape. Students who were chewing chat and having more than one sexual partner were at higher risk of experiencing rape as compared to non-chewers and no sexual partners respectively. Thus, Parents should make close follow up and give due attention to school female students; as much as possible female students better to attend their school living along with their family rather left alone or with their friends. The policy makers have to work on provision of comprehensive school based reproductive health education including, victimization prevention programs and life skill trainings must be provided besides the formal education to female high school students. Moreover Children, female, and youth affair office in Sodo town has to work on community mobilization and awareness creation with regard to Sexual Violence, perpetrators, how to report to legal bodies.

\section{Additional points}

Cross-sectional study design cannot answer questions involving past events with perfect accuracy. This either magnifies or minimizes the effects of certain variables, affecting the cross-sectional study's results. Thus, recall bias might adversely influence the results of the study.

\section{Authors' contributions}

Mekuanint Ayele: involved in conception, study design, analysis, and interpretation of the results.

Niguse Mekonnen: design of the study and data analysis, interpreted and wrote the manuscript.

Efrata Girma: participated in data analysis and manuscript write up.

Hailu Chare: data analysis, interpretation and prepared the manuscript.

All the authors read and approved the final manuscript.

\section{Acknowledgement}

It gives us a great pleasure to extend our heartfelt gratitude and appreciation for Wolaita Sodo University for giving us the chance to acquire valuable lessons and knowledge in public health. We would also like to thank Professor Yemane Berhane, Sodo Town Education, Mr. Aleme Mekuria, Mr. Tilahun Worku and Miss Alemtsehay Elias for the valuable comments and support whenever need arises.

Finally, we would like also to express our heartfelt gratitude to the study subjects.

\section{REFERENCES}

[1] WHO. Understanding and addressing violence against women, 2012.

[2] Sendo EG, Meleku M, Prevalence and factors associated with sexual violence among female students of Hawassa University in Ethiopia, Science Postprint, 2015; 1(2):e00047. 10.14340/spp.2015.04A0002.

[3] Kasangye et al, Sexual Violence at the Eastern Region of the Democratic Republic of Congo and its Public Health Implications, World J Public Health Sciences, 2014; 3(1):11.

[4] Nimani W, Hamdela B, Sexual Violence and Associated Factors among High School Students in Butajira Town, South Ethiopia. Gen Med (Los Angel) 2015; 3:1000196. doi:10.4172/23275146.1000196

[5] Haile R.T., Kebeta N.D. \& Kassie G.M. Prevalence of sexual abuse of male high school students in Addis Ababa, Ethiopia. BMC Int Health Hum Rights 2013; 13:24. https://doi.org/10.1186/1472698X-13-24

[6] Blake MT, Drezett J., Vertamatti M.A. et al. Characteristics of sexual violence against adolescent girls and adult women. BMC Women's Health 2014; 14:15. https://doi.org/10.1186/14726874-14-15

[7] Admas M, et al., Sexual Violence and Its Associated Factors among Regular Female Students in College of Medical Sciences, Jimma University, Southwest Ethiopia, J Womens Health Safety Res; 2017; 4(1):144-151.

[8] Jote M, Agumassie Semahegn, Balcha Berhanu: Assessment of sexual violence and associated factors among high school students in Harari Regional State, Harar Town, Eastern Ethiopia. Science Research, 2014; 2(5):91-97.

[9] Tora A. Assessment of sexual violence against female students in Wolaita Sodo University, Southern Ethiopia. J Interpers Violence, 2013; 28(11):2351-6.

[10] Miruts G. Prevalence and Factors Related to sexual and Physical Violence among Female high school and technical school students of Butajira, 2006; 5(6).

[11] Tsitsi P, Sexual Dilemma: Perceptions and Attitudes of Sexually Violated Women in Gweru Urban, Zimbabwe. Greener Journal of Social Sciences, 2013: 3(7).

[12] Joseph M. Chinawa \& A. E. Aronu \& B. F. Chukwu \& H. A. Obu, Prevalence and pattern of child abuse and associated factors in four secondary institutions in Enugu, Southeast Nigeria, Eur J Pediatr, 2013; 58(1):469-483.

[13] Haileye A. Psychopathological correlates of child sexual abuse: the case of female students in Jimma zone, South West Ethiopia. Ethiop J Health Sci. 2013; 23(1):32-38.

[14] Bizuayhu Shimekaw BM, Zelalem Alamrew. Prevalence and associated factors of sexual violence among private college female students in Bahir Dar city, North Western Ethiopia. Open access, 2013;5(6):1069-1075.

[15] Bekele AB, van Aken MA, Dubas JS. Sexual violence victimization among female secondary school students in eastern Ethiopia. Violence Vict. 2011; 26(5):608-630. doi:10.1891/0886-6708.26.5.608

\section{Conflicts of Interest: None}

